\title{
Age-Dependent Constraints of Sex Allocation in a Parasitoid Wasp
}

\author{
Takatoshi Ueno \\ Institute of Biological Control, Faculty of Agriculture, Kyushu University, Fukuoka 812-8581, Japan \\ Correspondence should be addressed to Takatoshi Ueno; ueno@grt.kyushu-u.ac.jp
}

Received 14 July 2014; Accepted 29 September 2014; Published 4 November 2014

Academic Editor: Jan Klimaszewski

Copyright (C) 2014 Takatoshi Ueno. This is an open access article distributed under the Creative Commons Attribution License, which permits unrestricted use, distribution, and reproduction in any medium, provided the original work is properly cited.

\begin{abstract}
The offspring sex ratios of parasitoid wasps often depend on the age of ovipositing females. Physiological constraints such as sperm depletion and senescence are a likely cause. Also, maternal control in response to female age may be an alternative explanation. Here valvifer or abdominal tip movements were used to assess whether age-dependent sex ratio was due to physiological constraints or maternal control with an ichneumonid wasp, Pimpla nipponica; the offspring sex ratio at the time of wasp emergence was compared with the sex ratio predicted from abdominal tip movements. When the female was relatively young, there was little difference between the sex ratios examined. However, as the age of the females increased, the realized offspring sex ratio at wasp emergence was more male-biased than the sex ratio predicted at the time of oviposition. Thus, there was an inconsistency between the sex ratios. Curiously, the predictions of continuous movements for male egg deposition were always perfect, regardless of maternal age; fertilization control failure was detected when the females had decided to lay female eggs. Thus, physiological constraints are a likely explanation for the inconsistency in relation to female age for P. nipponica.
\end{abstract}

\section{Introduction}

Arrhenotokous haplodiploid sex determination is common in the order Hymenoptera $[1,2]$. The sex determination mechanism allows the females to intentionally control the offspring sex ratio by controlling sperm access to eggs $[2,3]$. Indeed, sex ratios of many hymenopteran parasitoids are variable in response to a number of environmental factors, such as host size (= quality) and mating structure; the sex ratio variation can be understood only when we assume the maternal control of sex ratio [2-5].

A number of studies have shown that female wasps produce more male-biased sex ratio later in their life span $[3,6-8]$ though there was some exception [9]. The increased production of males, that is, unfertilized haploid eggs, may result from sperm depletion or reduced sperm viability. Also, control of sperm release from spermatheca may be weakened with maternal aging. In any case, physiological constraints are likely to be involved. Under some circumstances, however, maternal-age-dependent sex ratio can be an adaptive response; for example, when female wasps throughout their life have been given only large class of hosts, on which female eggs are usually laid when both small and large hosts are available, they may start to allocate male eggs in the later stage of their life [3]. If this is the case, female wasps intentionally modify the offspring sex ratio in response to their age or life expectancy.

Distinction between maternal control and physiological constraint is crucial to interpret the observed patterns of maternal-age-related sex ratio. Very few studies have provided the empirical evidence whether age-dependent sex ratio is due to maternal control or physiological constraint, however. A difficulty lies in distinguishing whether sex ratio patterns observed are caused by females' decision or by a physiological constraint such as sperm depletion. The majority of previous studies have examined the offspring sex ratio at the time of wasp emergence from the host, that is, realized sex ratio [3-5]. In some studies, sex ratios at the time of egg stage (primary sex ratio) were examined with chromosome observations [10-12] or DNA markers [13, 14] to compare with sex ratios at adult emergence (secondary sex ratio); the comparison can clarify the presence or absence of differential mortality between male and female offspring. However, such comparison does not provide any insight into 
the inconsistency between maternal decision and realized sex ratio.

Although it is usually difficult to assess the maternal decision to lay male or female eggs, predicting the decision is possible at least for several species of parasitoid wasps by observing female behavior during the oviposition. The most powerful method is the direct observation of abdominal tip movements of the ovipositing female, which can reflect fertilization action during the course of egg transfer from the common oviduct to the ovipositor $[15,16]$. The movements are continuous when she oviposits a male egg while they are interrupted once, an action during which sperm is probably released from spamatheca for fertilization, when a female egg is being laid. Thus, the abdominal tip movements during oviposition reflect the "decision of females."

The ichneumonid wasp Pimpla nipponica is a solitary idiobiont endoparasitoid attacking a variety of lepidopteran pupae [17-19] and is one of the species that show different abdominal tip movements, which enable predicting the sex of eggs that the female decides to lay [16]. Female P. nipponica respond to hosts of different size by changing sex allocation and allocate a higher proportion of female eggs in larger hosts $[10,12]$.

Here, the abdominal tip movements of $P$. nipponica were used to examine whether the offspring sex ratio at the time of wasp emergence was consistent with the sex ratio determined by maternal decisions. Particularly, the present study focused on a change of the sex ratio inconsistency in relation to the age of the ovipositing female. Based on the results, the evidence is given for the presence of sex ratio constrained by physiological causes.

\section{Materials and Methods}

2.1. Parasitoid and Host. A laboratory colony of P. nipponica was established using adult parasitoids collected from Nagoya City, Japan. Female $P$. nipponica were placed individually in transparent plastic cups $(10 \mathrm{~cm}$ in diameter, $4.5 \mathrm{~cm}$ in height), together with tissue paper saturated with diluted honey. The tissue paper was replaced twice a week thereafter. The cups were kept at $20 \pm 1^{\circ} \mathrm{C}$ with a $16 \mathrm{~L}: 8 \mathrm{D}$ photoperiod. The colony was maintained on pupae of a laboratory host, Galleria mellonella. Host cocoons containing fresh pupae were presented to the females in the plastic cups for parasitization. Parasitized hosts were removed from the cups and were held at $25 \pm 1^{\circ} \mathrm{C}$ with a $16 \mathrm{~L}: 8 \mathrm{D}$ photoperiod, until parasitoid emergence. Newly emerged parasitoids were paired and placed in the plastic cups and were maintained as mentioned above.

2.2. Sex Allocation Experiment. The sex of the offspring that $P$. nipponica decided to produce upon oviposition was predicted on the basis of the abdominal tip movements during oviposition (i.e., primary sex ratio) whereas sex ratios that were realized were examined at the time of offspring wasp emergence (i.e., secondary sex ratio). The movements may be continuous, or be interrupted once, during egg deposition, and the former movements indicate deposition of unfertilized eggs and the latter fertilized female eggs [16].

Newly emerged females were paired with a male in transparent plastic cups and observed to confirm successful mating. Care was taken to avoid sib-mating by using nonsib males. After mating, males were removed from the cups. Female $P$. nipponica for testing were reared at $20 \pm 0.5^{\circ} \mathrm{C}$, 16L:8D, during the experimental period. Twenty-two females in all were used for the experiment. Two host cocoons were given to the females in the cups for 2 hours twice a week after wasp emergence until death as a conditioning treatment. This treatment was needed to keep the females reproductive; an interruption of host provision for a relatively long period of time, for example, 1 or 2 weeks, can cause them having no eggs ready for oviposition (Ueno, personal observations).

Data were collected by arbitrarily giving 1-2 hosts to test females of 3-49 days old (the longevity of female P. nipponica is normally 35-45 days in the laboratory condition). Host cocoons containing a fresh pupa were offered singly to test females, and oviposition in the hosts was directly observed under a stereoscopic binocular microscope, recording abdominal tip movement patterns. Each female was allowed to attack a host only once to avoid superparasitism. Then, parasitized hosts were collected and kept singly at $25 \pm$ $1^{\circ} \mathrm{C}, 16 \mathrm{~L}: 8 \mathrm{D}$, until wasp emergence. When the offspring wasps emerged, the sex was recorded. Hosts that did not produce any wasp after 28-30 days since parasitization were discarded because the offspring wasps normally emerged within 3 weeks since parasitization [19].

Data were analyzed with the aid of JMP version 9.0 (SAS Institute, 2010). Fisher's exact probability test was used to evaluate the inconsistency of sex ratios. A logistic regression analysis was applied to examine the presence of age-related inconsistencies between predicted and realized sex ratios. This analysis was made with the data set for interrupted movements, in which production of male offspring was assumed to imply fertilization failure. Production of male or female offspring was a categorical dependent variable (binary variables) whereas maternal age was used as a continuous independent variable.

\section{Results}

In all, 196 hosts presented to test femaleswere parasitized. In 7 cases, the abdominal tip movements during oviposition were not recorded because the females did not oviposit an egg soon after the insertion of the ovipositor and became motionless with the ovipositor inserted in host. In 9 cases, judgment was difficult to classify the abdominal movements into continuous or interrupted because of the angle of vision for the observer. The above cases were excluded from the following analyses.

In all, continuous and interrupted movements were recorded for 85 and 95 parasitized hosts, respectively. Of these, 66 and 80 hosts, respectively, produced the offspring wasps. The results confirmed that the continuous and interrupted abdominal movements were mostly linked to the production of male and female offspring, respectively 
TABLE 1: Accuracy of abdominal tip movements for predicting the sex of offspring produced.

\begin{tabular}{lccccc}
\hline Movements & $N$ & $\begin{array}{c}\text { \% wasp } \\
\text { emergence }\end{array}$ & $\begin{array}{c}\text { Number of } \\
\text { females } \\
\text { produced }\end{array}$ & $\begin{array}{c}\text { Number of } \\
\text { males } \\
\text { emerged }\end{array}$ & $\begin{array}{c}\text { Sex ratio } \\
\text { (\% females) }\end{array}$ \\
\hline Continuous & 85 & 77.6 & 0 & 66 & 0 \\
Interrupted & 95 & 84.2 & 67 & 13 & 83.8 \\
\hline
\end{tabular}

(Table 1). Maternal control was perfect when female P. nipponica decided to lay male eggs (Table 1). By contrast, in 13 out of 80 cases $(16.3 \%)$, males were produced despite the interrupted movement. The result suggested that the failure of fertilization occurred even when the females tried to release sperm and fertilize eggs to produce female offspring. When all data were pooled regardless of female age, the percentage of failure of fertilization control differed significantly between the continuous and interrupted movements (Fisher's exact probability test; $\mathrm{df}=1, P=0.0003$ ). In addition, the failure of fertilization control was more likely to take place in older females (Figure 1). A logistic regression analysis revealed that the likelihood of fertilization control failure significantly increased with female age when the females tried to lay female eggs $\left(\mathrm{df}=1, x^{2}=4.72, P=0.029\right)$. The results demonstrated the presence of physiological constraints associated with female age.

\section{Discussion}

The present study has confirmed that abdominal tip movements are good predictors of the sex of depositing eggs. The movements, however, are not always perfect indices; male eggs were occasionally produced even when female P. nipponica showed interrupted movements. This inconsistency between the female's decisions and the realized sex of the offspring can be caused by physiological constraints. Constrained sex ratio in parasitoids should occur when females are unmated, sperm-depleted, senescent, or multiply mated [20-23] or male counterparts are of low quality [24, 25]. Females may be sperm-depleted in the late stage of their life when they have laid many fertilized eggs. Sperm depletion can also take place when females mate with low-quality males (e.g., small males) or multiply mated males $[23,25]$.

In the present study, evidence has shown that constrained sex ratio occurs for senescent $P$. nipponica; with increasing the age, the females were more likely to lay unfertilized male eggs despite their decisions to fertilize depositing eggs. This appears to be due to sperm depletion or physiological constraints associated with senescence. It also implies that an ovipositing female did not have a mechanism for assessing her physiological state.

In several parasitoids, the behavior of unmated females differs from that of mated females, suggesting that females can recognize their mating status $[26,27]$. In P. nipponica, however, unmated females behave as mated females; they show interrupted movements though they have no sperm in the spermatheca [16]. It is, hence, unlikely that female $P$. nipponica can recognize the number of sperms in the

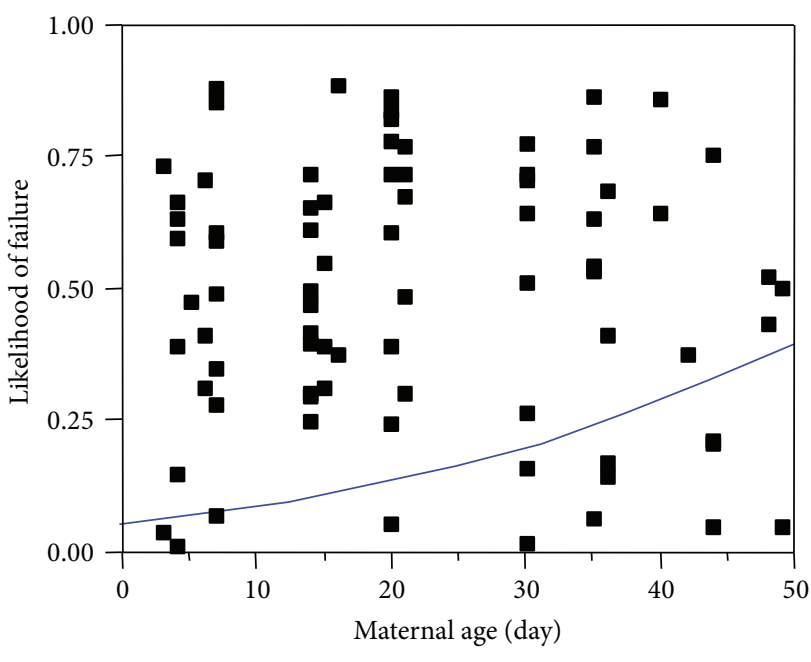

FIGURE 1: A logistic regression line obtained for the relationship between maternal age and likelihood of fertilization failure. The points are placed midway to assure their visibility, and the horizontal placement of each point (= one oviposition event) is made with respect to the horizontal axis (= female wasp age). The points above or below the curve show data set in which test females produced female or male offspring (see JMP User's Guide).

spermatheca; the senescent females would not modify their sex allocation in response to sperm depletion.

Curiously, senescence did not influence the consistency between the continuous movements and the deposition of unfertilized male eggs. This result indicates that sperm is never wrongly released regardless of female age. I suggest that the exit of sperm from spermatheca is normally closed, and senescence affects only the control to open the exit for sperm release to fertilize the eggs.

Parasitoid wasps have been shown to be excellent organisms for testing sex ratio theory $[1,4,12,28]$. However, sex ratio theory generally assumes perfect maternal control over the offspring sex allocation. In fact, constrained sex ratio does occur in several parasitoid wasps, mostly due to unmatedness, and the presence of constrained unmated females should lead to the production of a more female-biased sex ratio by nonconstrained mated females than predicted [2022]. This means that constrained females influence the sex allocation decision of other nonconstrained females.

Likewise, senescent $P$. nipponica females can be constrained from perfectly controlling the offspring sex ratio, and the consequence is the production of large males from large hosts, which should normally produce female offspring. The presence of constrained females may affect the overall sex 
ratio produced by nonconstrained females, and the latter may produce a more female-biased sex allocation to a given size of hosts than predicted. However, in the field, females should have a shorter life span than physiologically attainable span, and females that are constrained due to senescence should be rather rare. Given this, the impact of constrained females may not be large. In any case, the effect of constrained females on the sex ratio produced by nonconstrained females would be a future subject.

\section{Conflict of Interests}

The author declares that there is no conflict of interests regarding the publication of this paper.

\section{Acknowledgments}

The author thanks an anonymous reviewer for his (or her) valuable comments and suggestions to improve the paper. This work was partly supported by Grant-in-Aid for Basic Research (C), Japan Society for the Promotion of Science (Research Project no. 24580079).

\section{References}

[1] H. C. J. Godfray, Parasitoids: Behavioral and Evolutionary Ecology, Princeton University Press, Princeton, NJ, USA, 1994.

[2] I. C. W. Hardy, Sex Ratios: Concepts and Research Methods, Cambridge University Press, Cambridge, UK, 2002.

[3] B. H. King, "Offspring sex ratios in parasitoid wasps," Quarterly Review of Biology, vol. 62, no. 4, pp. 367-396, 1987.

[4] B. H. King, "Sex ratio manipulation by parasitoid wasps," in Evolution and Diversity of Sex Ratio in Insects and Mites, D. L. Wrensch and M. Ebbert, Eds., pp. 418-441, Chapman \& Hall, New York, NY, USA, 1993.

[5] P. J. Ode and I. C. W. Hardy, "Parasitoid sex ratios and biological control," in Behavioral Ecology of Insect Parasitoids, E. Wajnberg, C. Bernstein, and J. van Alphen, Eds., pp. 253-291, Blackwell, Malden, Mass, USA, 2008.

[6] H. Nadel and R. F. Luck, "Span of female emergence and male sperm depletion in the female-biased, quasi-gregarious parasitoid, Pachycrepoideus vindemiae (Hymenoptera: Pteromalidae)," Annals of the Entomological Society of America, vol. 78, pp. 410-414, 1985.

[7] S. Pandey and R. Singh, "Effect of parental age at coition on reproduction of Lysiphlebia mirzai (Hymenoptera: Braconidae)," Entomologia Generalis, vol. 23, no. 3, pp. 187-193, 1998.

[8] S. Santolamazza-Carbone, M. P. Nieto, and A. C. Rivera, "Maternal size and age affect offspring sex ratio in the solitary egg parasitoid Anaphes nitens," Entomologia Experimentalis et Applicata, vol. 125, no. 1, pp. 23-32, 2007.

[9] D. Damiens, C. Bressac, and C. Chevrier, "The effect of age on sperm stock and egg laying in the parasitoid wasp, Dinarmus basalis," Journal of Insect Science, vol. 3, p. 22, 2003.

[10] T. Ueno and T. Tanaka, "Comparison between primary and secondary sex ratios in parasitoid wasps using a method for observing chromosomes," Entomologia Experimentalis et Applicata, vol. 82, no. 1, pp. 105-108, 1997.

[11] T. Ueno, "Sex allocation by a parasitoid wasp (Hymenoptera: Ichneumonidae) to different host species: a question for the mechanism of host size estimation," Journal of Insect Behavior, vol. 11, no. 6, pp. 811-821, 1998.

[12] T. Ueno, "Host-size-dependent sex ratio in a parasitoid wasp," Researches on Population Ecology, vol. 41, no. 1, pp. 47-57, 1999.

[13] J. Abe, Y. Kamimura, M. Shimada, and S. A. West, "Extremely female-biased primary sex ratio and precisely constant male production in a parasitoid wasp Melittobia," Animal Behaviour, vol. 78, no. 2, pp. 515-523, 2009.

[14] S. K. Khidr, S. Mayes, and I. C. W. Hardy, "Primary and secondary sex ratios in a gregarious parasitoid with local mate competition," Behavioral Ecology, vol. 24, no. 2, pp. 435-443, 2013.

[15] L. R. Cole, "A visible sign of a fertilization action during oviposition by an ichneumonid wasp, Itoplectis maculator," Animal Behaviour, vol. 29, no. 1, pp. 299-300, 1981.

[16] T. Ueno, "Abdominal tip movements during oviposition by two parasitoids (Hymenoptera: Ichneumonidae) as an index of predicting the sex of depositing eggs," Applied Entomology and Zoology, vol. 30, pp. 588-590, 1995.

[17] K. Yasumatsu and C. Watanabe, A Tentative Catalogue of Insect Natural Enemies of Injurious Insects in Japan. Part 2. Host Parasite-Predator Catalogue, Kyushu University Press, Fukuoka, Japan, 1965.

[18] H. Townes, S. Momoi, and M. Townes, "A catalogue and reclassification of the eastern palearctic Ichneumonidae," Memoirs of American Entomological Institute, no. 5, 1965.

[19] T. Ueno and T. Tanaka, "Comparative biology of six polyphagous solitary pupal endoparasitoids (Hymenoptera: Ichneumonidae): differential host suitability and sex allocation," Annals of the Entomological Society of America, vol. 87, pp. 592-598, 1994.

[20] I. C. W. Hardy and H. C. J. Godfray, "Estimating the frequency of constrained sex allocation in field populations of Hymenoptera," Behaviour, vol. 114, no. 1, pp. 137-147, 1990.

[21] H. C. J. Godfray and I. C. W. Hardy, "Sex ratio and virginity in haplodiploid insects," in Evolution and Diversity of Sex Ratio in Insects and Mites, D. L. Wrensch and M. Ebbert, Eds., pp. 418441, Chapman \& Hall, New York, NY, USA, 1993.

[22] I. C. W. Hardy and J. M. Cook, "Brood sex ratio variance, developmental mortality and virginity in a gregarious parasitoid wasp," Oecologia, vol. 103, no. 2, pp. 162-169, 1995.

[23] G. Boivin, "Sperm as a limiting factor in mating success in Hymenoptera parasitoids," Entomologia Experimentalis et Applicata, vol. 146, no. 1, pp. 149-155, 2013.

[24] H. J. Henter, "Constrained sex allocation in a parasitoid due to variation in male quality," Journal of Evolutionary Biology, vol. 17, no. 4, pp. 886-896, 2004.

[25] B. H. King and C. R. Fischer, "Male mating history: effects on female sexual responsiveness and reproductive success in the parasitoid wasp Spalangia endius," Behavioral Ecology and Sociobiology, vol. 64, no. 4, pp. 607-615, 2010.

[26] B. H. King, "Breeding strategies in females of the parasitoid wasp Spalangia endius: effects of mating status and size," Journal of Insect Behavior, vol. 15, no. 2, pp. 181-193, 2002.

[27] D. Gottlieb, Y. Lubin, and A. R. Harari, "The effect of female mating status on male offspring traits," Behavioral Ecology and Sociobiology, vol. 68, no. 5, pp. 701-710, 2014.

[28] T. Ueno, "Adaptiveness of sex ratio control by the pupal parasitoid Itoplectis naranyae (Hymenoptera: Ichneumonidae) in response to host size," Evolutionary Ecology, vol. 12, no. 6, pp. 643-654, 1998. 

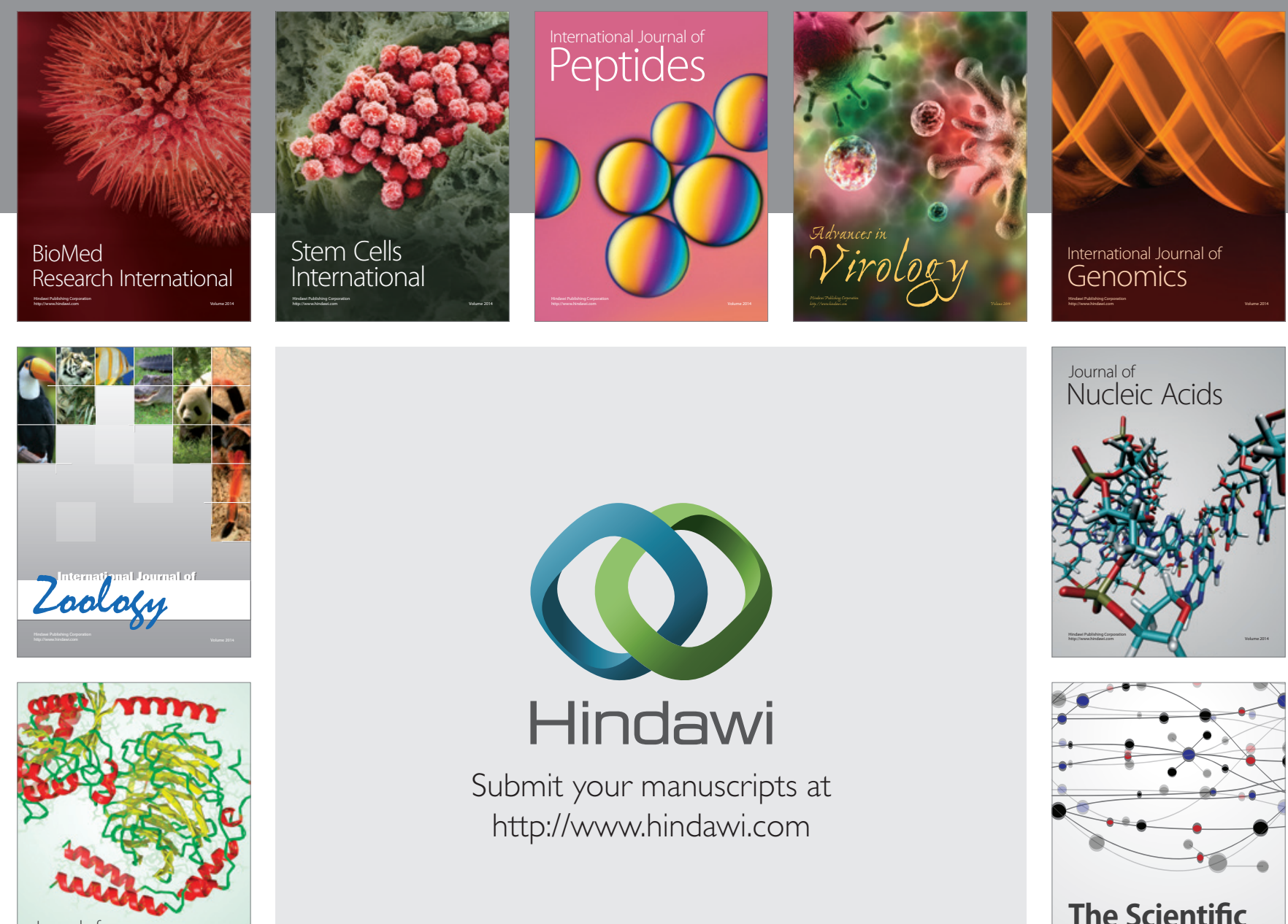

Submit your manuscripts at

http://www.hindawi.com

Journal of
Signal Transduction
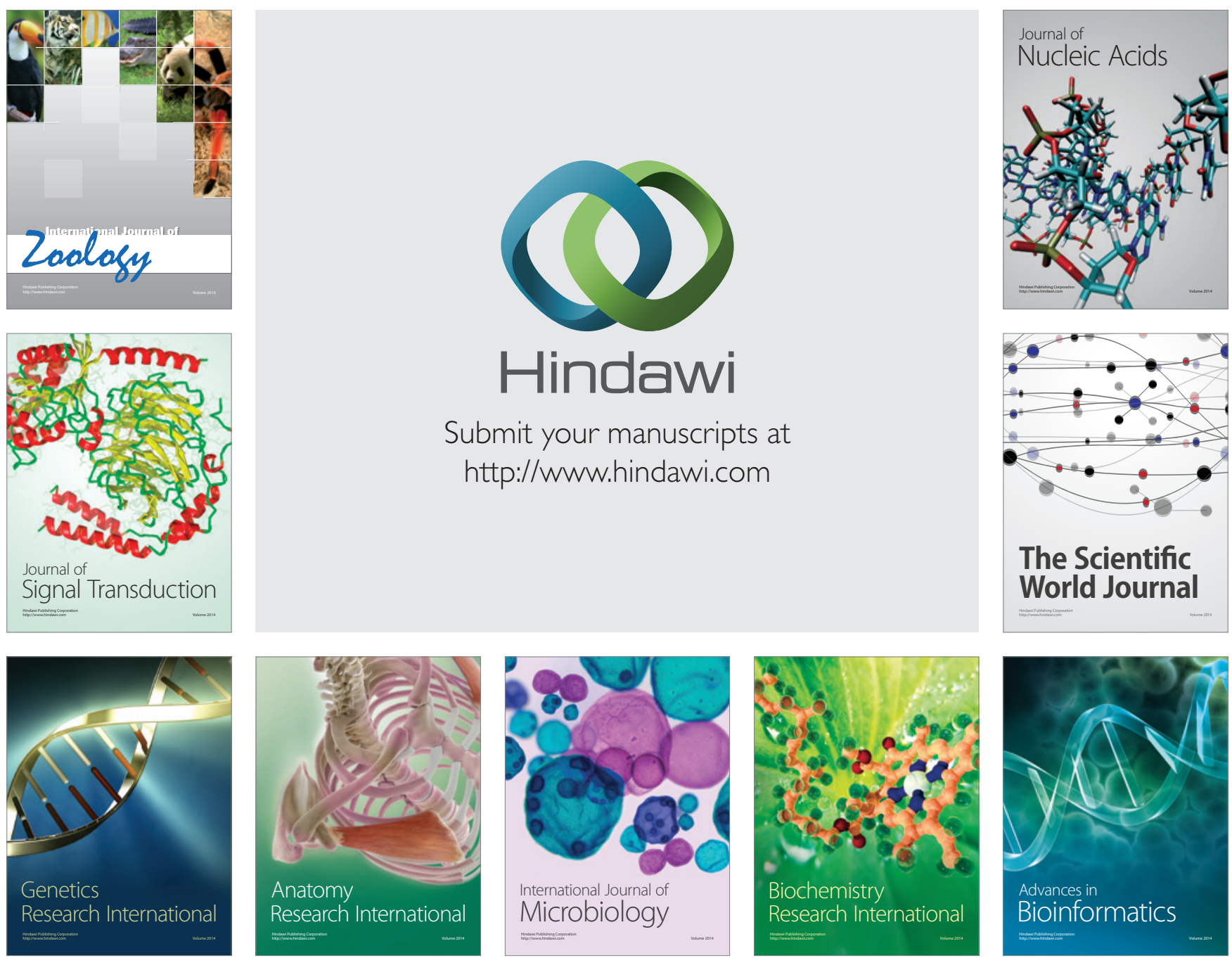

The Scientific World Journal
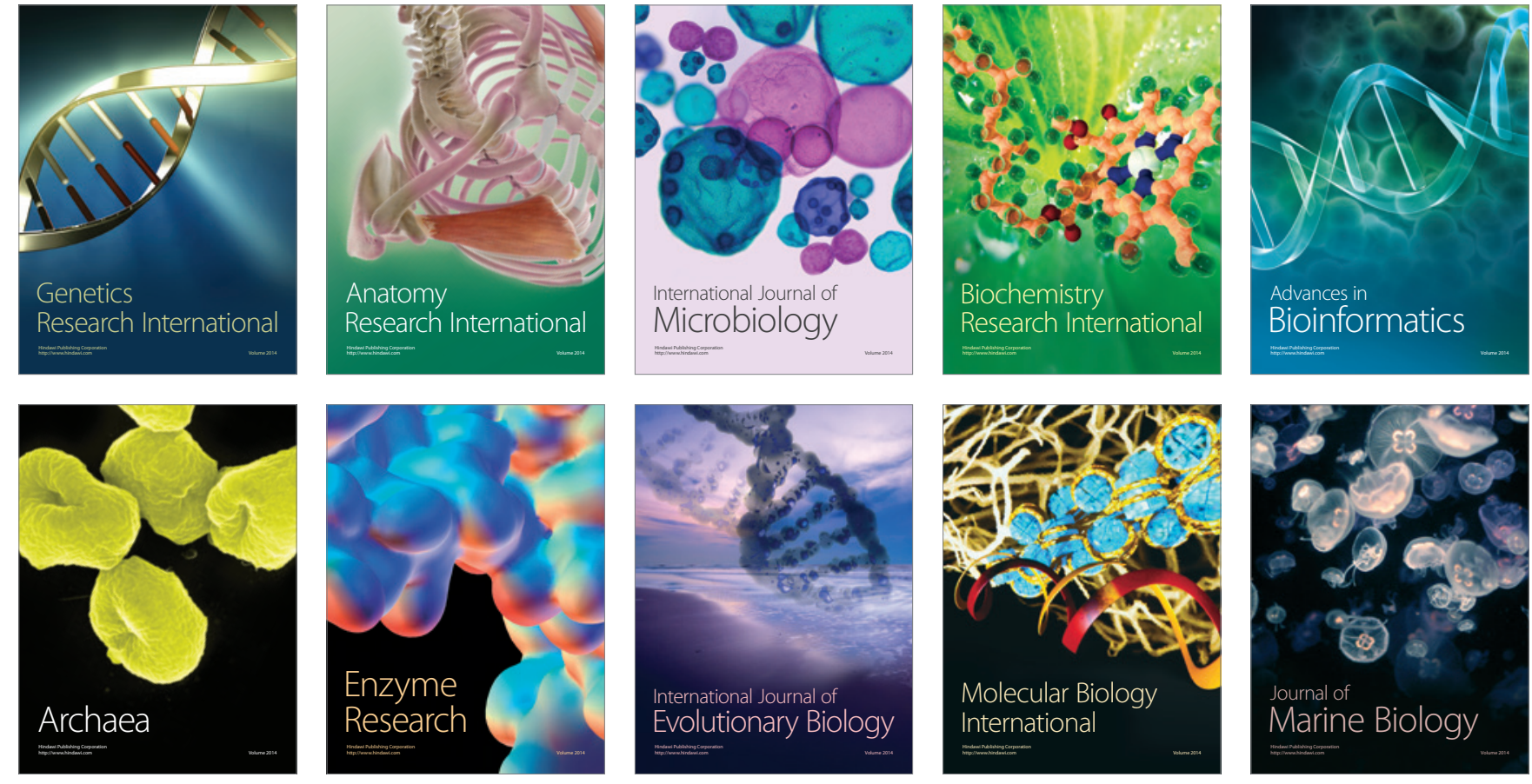